\title{
Electric Properties of Conducting Composite from Poly(ethylene oxide) and Poly(ethylene oxide)-Grafted Carbon Black in Solvent Vapor
}

\author{
Jinhua CHEN and Norio TSUBOKAWA ${ }^{*}+$ \\ Graduate School of Science and Technology, Niigata University, \\ 8050 Ikarashi 2-nocho, Niigata 950-2181, Japan \\ *Department of Material Science and Technology, Faculty of Engineering, \\ Niigata University, 8050, Ikarashi 2-nocho, Niigata 950-2181, Japan
}

(Received January 7, 2000; Accepted May 2, 2000)

\begin{abstract}
A conducting composite from high molecular weight poly(ethylene oxide) (PEO) and low molecular weight PEO-grafted carbon black (CB) was prepared. The electric resistance of the composite in dry air and chloroform vapor was examined. The effects of many factors, such as CB content, $C B$ type and its dispersion in composite, and thickness of the composite film, on the ratio of electric resistance of the composite in dry air $\left(R_{0}\right)$ and in chloroform vapor $(R)$, defined as responsiveness $\left(R / R_{0}\right)$ of the conducting composite, were investigated. For both $\mathrm{CB}$ (Porousblack and Asahi $60 \mathrm{H}$ black) used in this study, at CB content of $20-50 \mathrm{wt} \%$, the responsiveness is high over $10^{4}$ time. In the case of low $\mathrm{CB}$ content, the responsiveness is lower than 0.1. To explain the responsiveness of the composite for high and low $\mathrm{CB}$ content, two conduction mechanisms were proposed. To clarify the relationship between responsiveness and amount of vapor absorption, a method to simultaneously determine the resistance and vapor absorption amount of the composite was developed.

KEY WORDS Carbon Black / Poly(ethylene oxide) / Conducting Composite / Surface Grafting / Gas Sensor/
\end{abstract}

The electrical resistance of insulation polymer filled with carbon black (CB) decreases discontinuously at a particular content of $\mathrm{CB}$, generally defined as the percolation threshold. ${ }^{1-4}$ Besides wide applications of percolation of conducting composites, these composites also often used as PTC (positive temperature coefficient) materials $^{5-8}$ or gas sensors ${ }^{9-14}$ at $\mathrm{CB}$ content above the percolation threshold.

PTC behavior of polymer/CB composite has been intensively studied. However, the mechanism of drastic change of electric resistance is not completely understood. The mechanism of negative temperature coefficient (NTC) behavior, which appears above the melting point of the polymer, is also unresolved.

$\mathrm{CB} /$ polymer composite as a gas sensor was studied previously. ${ }^{9-12}$ The electric resistance of the composite from polymer-grafted CB and crystalline polymer increased several orders of the magnitude in some solvent vapors. The large responsiveness of the composite against certain vapors may result from a conducting network in the composite when it is cut by the dissolved crystalline polymer during solvent vapor absorption.

Crystalline polymer melting at the melting point and dissolving in solvent are similar to each other. Both processes result in the polymer chain moving more freely, polymer volume swelling and composite viscosity decrease. This might be the same mechanism for large electric resistance change when the temperature is increased and solvent vapor is absorbed.

In the present paper, the electrical properties of the composite from high molecular weight poly(ethylene oxide) (PEO) and low molecular weight PEO-grafted CB were studied. The effects of $\mathrm{CB}$ type and content in composite, on the gas responsiveness of electric resistance to

\footnotetext{
${ }^{\dagger}$ To whom correspondence should be addressed.
}

chloroform vapor, were investigated in detail. The effects of film thickness of the composite and CB dispersion in the composite on the responsiveness were also investigated. The composite could be used as a gas sensor, and we propose two conduction mechanisms to explain the electric resistance change in solvent vapor.

\section{EXPERIMENTAL}

\section{Materials}

PEO with different molecular weights $\left(M_{n}=1540\right.$ and $1.0 \times 10^{5}$ ) were purchased from Aldrich and used as received. PEO with high $M_{n}$ was used as a matrix in the composite, and the low one as a surface modification agent to graft onto $\mathrm{CB}$ particles. Two conductive $\mathrm{CB}$ were used as fillers. One, Porousblack, has high specific surface area, $447 \mathrm{~m}^{2} \mathrm{~g}^{-1}$, and the other, Asahi $60 \mathrm{H}$ black, lower specific surface area, $60 \mathrm{~m}^{2} \mathrm{~g}^{-1}$. The properties of CB are shown in Table I. Both were obtained from Asahi Carbon Co. Ltd., Japan, and dried in a vacuum at $110^{\circ} \mathrm{C}$ for $48 \mathrm{~h}$ before use.

4,4-Azobis(4-cyanopentanoic acid) (ACPA), used for the introduction of $\mathrm{PEO}$ grafting sites onto the CB surface, was purchased from Wako Pure Chemical Inc. Ltd., Japan and purified by recrystallization from a methanol solution.

Table I. Properties of carbon black used in study

\begin{tabular}{|c|c|c|c|c|}
\hline \multirow{2}{*}{ Carbon black } & Specific surface area & Particle size & $\overline{\mathrm{DBP}^{\mathrm{a}}}$ & PEO-grafting \\
\hline & $\mathrm{m}^{2} \mathrm{~g}^{-1}$ & $\mathrm{~nm}$ & $\mathrm{~mL} / 100 \mathrm{~g}$ & wt $\%$ \\
\hline \multirow{2}{*}{$\begin{array}{l}\text { Porousblack } \\
\text { Asahi } 60 \mathrm{H} \\
\text { black }\end{array}$} & 447 & 41 & 166 & 6.4 \\
\hline & 60 & 41 & 124 & 2.0 \\
\hline
\end{tabular}

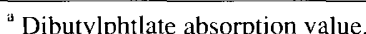



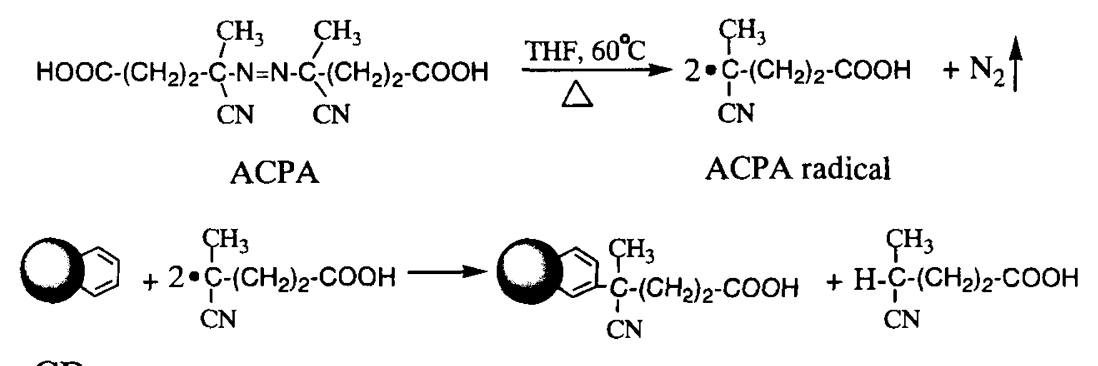

CB

$\mathrm{COOH}$ introduced $\mathrm{CB}$

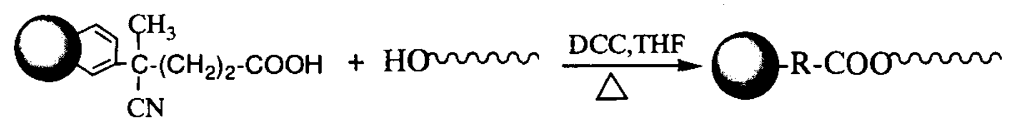

$$
\begin{aligned}
& \text { PEO PEO-grafted CB }
\end{aligned}
$$

Scheme 1. Grafting of PEO onto carbon black surface.

\section{PEO Grafting onto CB Surface}

Similar treatment as in our previous paper was conducted to graft PEO onto CB surface, ${ }^{10}$ as shown in Scheme 1 .

Radicals formed by thermal decomposition of ACPA were terminated by the CB surface to form a preliminary treated surface with surface carboxyl groups. PEO was reacted with the carboxyl groups by direct condensation with terminal hydroxyl groups by $N, N^{\prime}$-dicyclohexylcarbodiimide (DCC) as condensing agent. Grafted layer on the $\mathrm{CB}$ surface was measured by $\mathrm{TGA}^{11}$ and is shown in Table I.

\section{Preparation of Composite from PEO-Grafted $C B$ and PEO}

The preparation of $\mathrm{PEO} / \mathrm{CB}$ composite was performed by the solution method. Into a $100 \mathrm{~mL}$ flask, $0.4 \mathrm{~g}$ PEO $\left(M_{n}=1.0 \times 10^{5}\right)$ and $10 \mathrm{~mL}$ of chloroform were added. After PEO dissolved completely, weighed PEO-grafted CB was added to the solution and $\mathrm{CB}$ was dispersed by stirring with a magnetic stirrer or by ultrasonic irradiation at room temperature. The suspension was cast on a comb-like electrode, prepared by screen-printing of conductive $\mathrm{Ag} / \mathrm{Pd}$ paste onto a ceramic plate, as shown in Figure 1. The cast $\mathrm{PEO} / \mathrm{CB}$ composite film on the electrode had an area of $4 \times 7 \mathrm{~mm}^{2}$, and thickness of $12 \mu \mathrm{m}$.

Electric resistance of the composite in solvent vapor was measured by hanging the electrode coated with composite in a glass tube containing pure solvent at the bottom. The distance between the composite and solvent surface was $2.0 \mathrm{~cm}$. DC electric resistance was measured by an ohmmeter (a digital multimeter, made by Advantest Co. Ltd., Japan; type R6871E-DC), and resistance was read by a personal computer. ${ }^{11}$

To clarify the relationship between the electric resistance responsiveness and vapor absorption of the composite, we developed a new technique, as shown in Figure 1 , to simultaneously determine electric resistance and vapor absorption amount. Change in composite weight in chloroform vapor, considered the chloroform absorbed, was determined by Sartorious Basic-plus Bal-

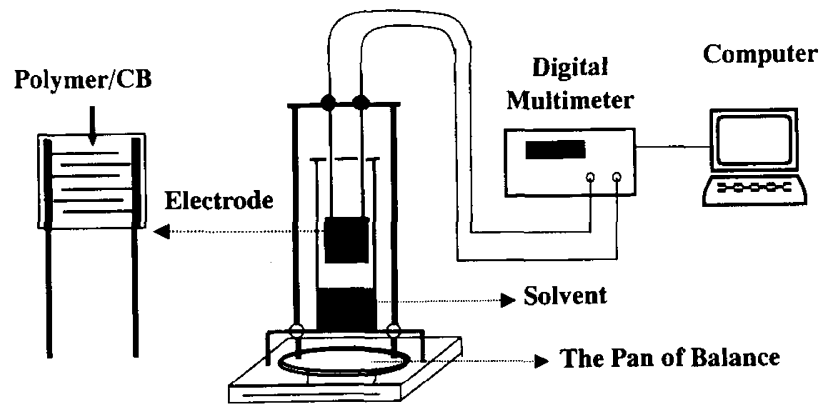

Figure 1. Comb-like electrode and apparatus for measurement of electric resistance.

ance (Sartorious Co., Japan).

\section{RESULTS AND DISCUSSION}

Effects of CB Content on Initial Electric Resistance of the Composite from PEO and PEO-Grafted $C B$

Figure 2 shows the relationship between $\mathrm{CB}$ content and electric resistance of the PEO/CB composite. Generally, the resistance decreased very sharply after reaching the percolation threshold $\left(\mathrm{C}^{*}\right)$, which strongly depended on the filler, as expected. Two different $\mathrm{CB}$, showed nearly the same electric resistance change. However, for $\mathrm{CB}$ (Porousblack) with higher specific surface area, the content for reaching the percolation threshold was smaller than $\mathrm{CB}$ (Asahi $60 \mathrm{H}$ black) with lower specific surface area.

In the case of low $\mathrm{CB}$ content, electric resistance is very high over $1200 \mathrm{M} \Omega$ (maximum resistance we can determine with digital multimeter), indicating no conducting network for electric current, and CB particles are isolated in the composite. With increasing CB content to a critical $\mathrm{CB}$ weight fraction (percolation threshold), the CB network is formed in the composite, which leads to drastic decrease in electric resistance. The two $\mathrm{CB}$, Porousblack and Asahi $60 \mathrm{H}$ black, have the same average particle size but the former has a large specific 


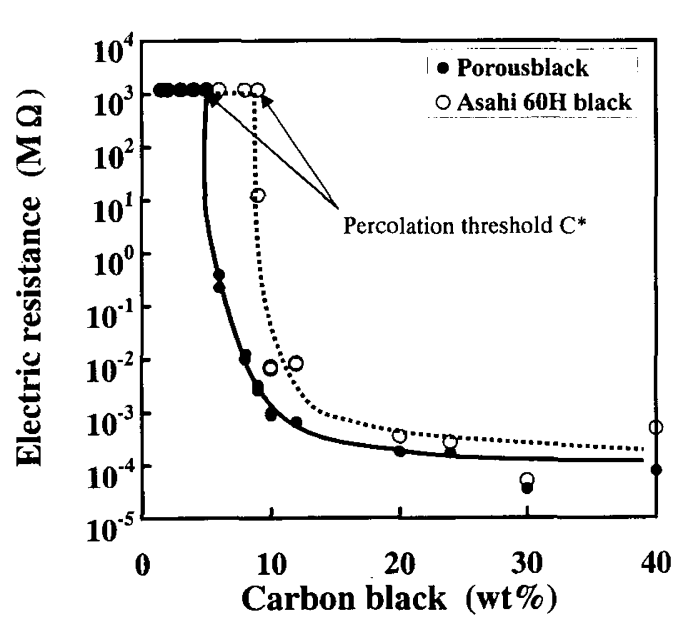

Figure 2. Electric resistance of the composite from $\mathrm{PEO}$ and PEO-grafted CB, determined in dry air, as a function of $\mathrm{CB}$ content.

area of $447 \mathrm{~m}^{2} \mathrm{~g}^{-1}$ and the latter, only $60 \mathrm{~m}^{2} \mathrm{~g}^{-1}$. As shown in Figure 2, with the same CB content, electric resistance of composite from the Porousblack is lower than that from Asahi $60 \mathrm{H}$ black. In terms of the percolation threshold $\mathrm{C}^{*}$, it is $6 \mathrm{wt} \%$ for Porousblack, but about $10 \mathrm{wt} \%$ for Asahi $60 \mathrm{H}$, which is clearly higher than the former. It is not clear why Porousblack has lower percolation threshold than Asahi $60 \mathrm{H}$.

From the percolation theory, ${ }^{3,15}$ for ideal uniform spherical $\mathrm{CB}$ dispersion in a polymer, the percolation threshold is about 16 vol\% (in the case of weight fraction, $25 \mathrm{wt} \%$ ). At low percolation value of less than $10 \mathrm{wt} \%, \mathrm{CB}$ can be considered to disperse only in the amorphous region in a $\mathrm{PEO}$ matrix. Therefore, fairly higher $\mathrm{CB}$ in the amorphous region of $\mathrm{PEO}$ leads to lower $\mathrm{CB}$ in the composite to reach the percolation threshold. The crystalline region, as it is dense and an ideal structure, is hardly penetrated by CB particles. ${ }^{5,16,17} \mathrm{CB}$ particles are thus densely packed into the crystalline boundary, which makes the conducting particles to more closely to form a carbon "chain" which allows current to flow through the composite and thus leads to lower electric resistance in the crystalline polymer/CB composite.

Effects of $C B$ Content on Electric Resistance of the Composite from $\mathrm{PEO}$ and $\mathrm{PEO}$-Grafted $\mathrm{CB}$ in Chloroform Vapor

Measurement data of $\mathrm{CB} /$ polymer composite electric resistance is largely influenced by the detection environment. ${ }^{18}$ That is, electric resistance of the composite largely increases in the water or other solvent vapors. Therefore, electric resistance is usually measured in a dry atmosphere. Our gas sensor study reported that electric resistance of the composite from polymer-grafted $\mathrm{CB}$ is $10^{4}-10^{6}$ times higher in a certain vapor than in dry air. ${ }^{11,12}$ We also reported similar PTC of the composite form low density polyethylene (LDPE) and poly(ethylene-block-ethylene oxide) (PE-b-PEO)-grafted CB in cyclohexane vapor and the electric resistance is much higher than that in dry air. ${ }^{12}$

Figure 3 shows the electric resistance of $\mathrm{PEO} / \mathrm{CB}$ com-

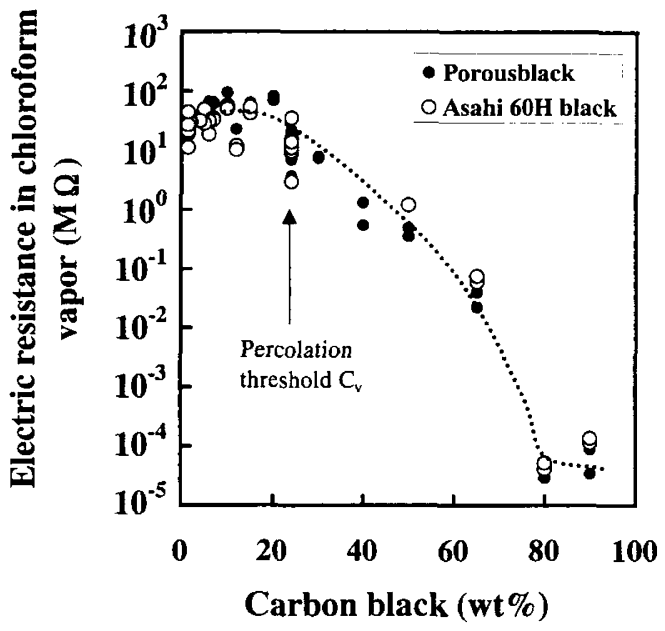

Figure 3. Electric resistance of the composite from $\mathrm{PEO}$ and $\mathrm{PEO}$-grafted $\mathrm{CB}$, determined in chloroform vapor, as a function of CB content.

posite with different $\mathrm{CB}$ and various $\mathrm{CB}$ content in chloroform vapor at $25^{\circ} \mathrm{C}$. There is appears no any clear difference between the two $\mathrm{CB}$, but the percolation thresholds in chloroform vapor $\mathrm{C}_{\mathrm{v}}$ are much higher than in dry air. Above the content of the percolation threshold $C_{v}$, electric resistance is not so quickly decreased, resulting in a very wider percolation region of about $24-80 \mathrm{wt} \%$. Both percolation thresholds $\mathrm{C}_{\mathrm{v}}$ are about $24 \mathrm{wt} \%$. This agrees with the percolation theoretical value, indicating that the dispersion of $\mathrm{CB}$ particles in the composite is extremely uniform. In other words, the crystalline polymer in the composite is dissolved by absorbed chloroform vapor, which permits the dissolved chain to move to the $\mathrm{CB} /$ amorphous polymer region and/or the $\mathrm{CB}$ particles move into the dissolved crystalline polymer region. This leads to uniform dispersion in the composite. Without the crystalline structure, CB particles in the conducting network connect loosely, leading to high electric resistance even above the percolation threshold.

Responsiveness of Electric Resistance of Composite from $P E O$ and $P E O$-Grafted $C B$ against Chloroform

Electric resistance of composite from PEO and PEOgrafted CB had different values in dry air and chloroform vapor. This means the composite responded to the chloroform vapor through electric resistance change. Our previous paper ${ }^{11,12}$ defined responsiveness as the ratio of electric resistance in solvent vapor and in dry air. We reported the responsiveness of crystalline polymer/CB composites with polymer-grafted $\mathrm{CB}$, such as $\mathrm{PE}-b$-PEO/CB, LDPE/CB composite, to be sensitive, stable and reproducible for some solvent vapors. The responsiveness of electric resistance of the composites from $\mathrm{PEO}$ and $\mathrm{PEO}$-grafted $\mathrm{CB}$, with various $\mathrm{CB}$ content and two $\mathrm{CB}$ was examined. The results are shown in Figures 4 and 5 .

In the initial $60 \mathrm{~s}$, electric resistance of the composite was measured in dry air as initial resistance, $R_{0}$. The composite was exposed to chloroform vapor for $180 \mathrm{~s}$ and returned to dry air. Responsiveness to chloroform vapor was calculated by $R / R_{0}$, and is plotted in Figures 4 and 5 .

Figure 4 shows the responsiveness of electric resis- 


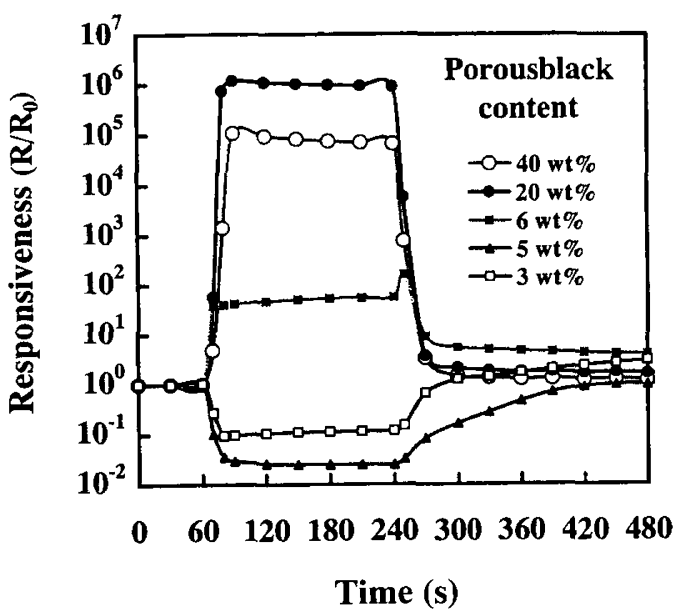

Figure 4. Responsiveness of electric resistance of the composite from PEO and different content of PEO-grafted Porousblack to chloroform vapor at $25^{\circ} \mathrm{C}$.

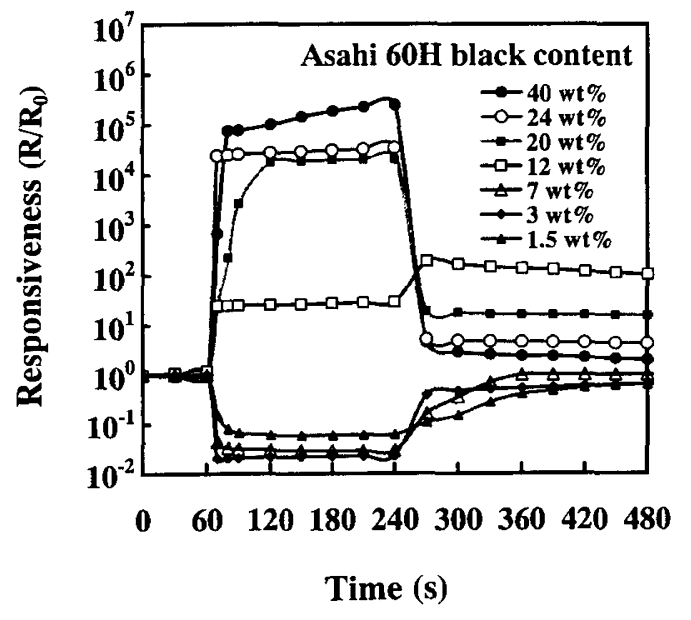

Figure 5. Responsiveness of electric resistance of the composite from PEO and different content of PEO-grafted Asahi $60 \mathrm{H}$ black to chloroform vapor at $25^{\circ} \mathrm{C}$.

tance of the composite from PEO and PEO-grafted Porousblack with various $\mathrm{CB}$ content. In the case of $\mathrm{CB}$ content over the percolation threshold $(20 \mathrm{wt} \%$ and $40 \mathrm{wt} \%$ ), electric resistance is $10^{5}-10^{6}$ times the initial electric resistance.

In disagreement with the general predicted, the largest responsiveness was not observed near the percolation threshold $\mathrm{C}^{*}$. In fact, at or near the percolation threshold ( $6 \mathrm{wt} \%$ Porousblack), responsiveness was small and unstable. Electric resistance also does not return to the initial value when the composite is transferred to dry air. In comparison with the high responsiveness of the composite in the case of high CB content, it is interesting to note that below the percolation threshold ( $3 \mathrm{wt} \%$ and $5 \mathrm{wt} \%$ ), electric resistance decreases to $10^{-1}-10^{-2}$ the initial resistance, which may mean a different conducting mechanism in the composite.

Figure 5 shows the responsiveness of electric resistance of the composite from PEO and PEO-grafted Asahi

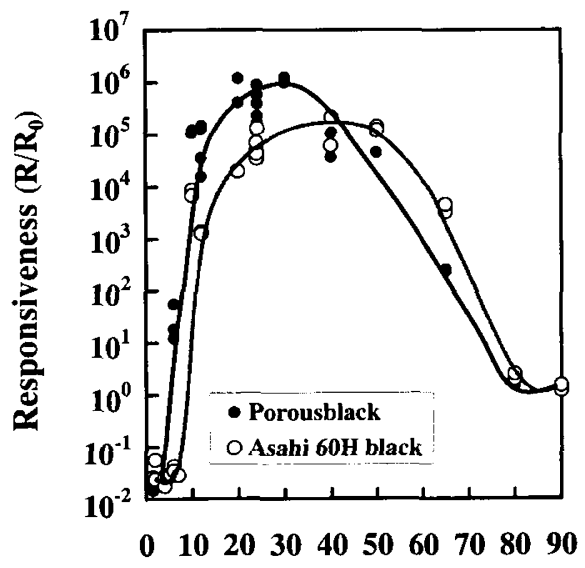

Carbon black (wt\%)

Figure 6. Relationship between responsiveness and $\mathrm{CB}$ content for two CB in PEO and PEO-grafted CB composite.

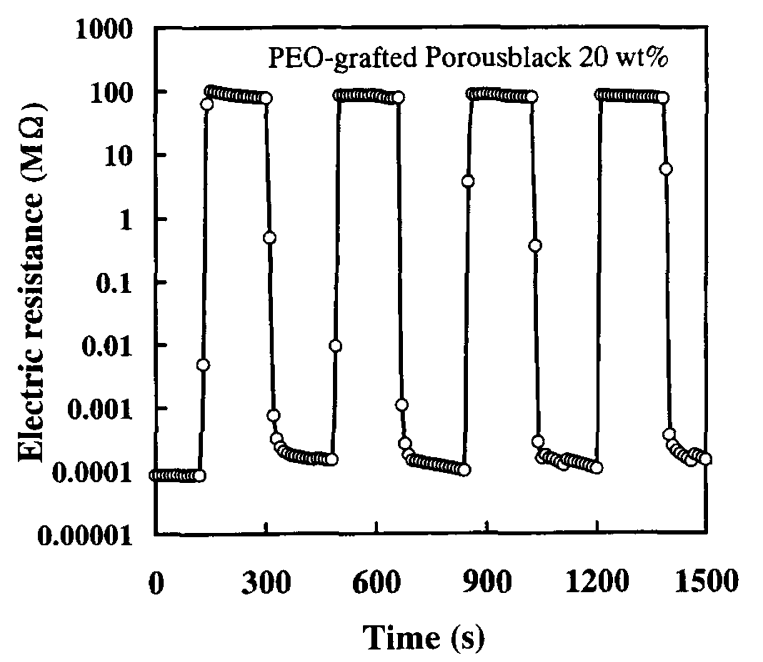

Figure 7. Typical responsiveness of electric resistance of the composite from $\mathrm{PEO}$ and $\mathrm{PEO}$-grafted $\mathrm{CB}$ on four repeated exposures to the saturated chloroform vapor at $25^{\circ} \mathrm{C}$.

$60 \mathrm{H}$ black with various $\mathrm{CB}$ content. The results are very similar to those from Porousblack, which further support the results of Porousblack-containing composite.

Figure 6 shows the effects of $\mathrm{CB}$ content on the vapor responsiveness of the composites. In the case of $\mathrm{CB}$ content at $20-40 \mathrm{wt} \%$, the responsiveness of electric resistance of the composite from Porousblack is higher than that from Asahi $60 \mathrm{H}$ black. But above $40 \mathrm{wt} \% \mathrm{CB}$ content, the responsiveness of composite from Asahi $60 \mathrm{H}$ black is higher than that of Porousblack. It seems that the two CB have the same attribution to the responsiveness of electric resistance of the composite to chloroform vapor. However, Porousblack is more efficiency on the composite responsiveness, i.e., the responsiveness curve of Porousblack shifts to low CB content as shown in Figure 6. The same is observed in Figure 3. With high specific surface area, the Porousblack is more easily aggregated to form conducting network in the composite and is more effective on the responsiveness of the composite to vapors. 
Maximum responsiveness of the composite from the two $\mathrm{CB}$ does not appear at or near the percolation threshold $\mathrm{C}^{*}$ in air, but is fairly far from $\mathrm{C}^{*}$. $\mathrm{CB}$ content, where the maximum responsiveness appears, is near the percolation threshold $\mathrm{C}_{\mathrm{v}}$ (about $24 \mathrm{wt} \%$ as shown in Figure 3) in chloroform vapor.

At the CB content near $\mathrm{C}_{\mathrm{v}}$, responsiveness is very sensitive and stable, and electric resistance immediately returns to its initial resistance when the composite is transferred to dry air. Figure 7 shows a typical responsiveness of the composites to chloroform vapor. It is apparent that responsiveness of these composites was reproducible and stable in every cycle of exposure to chloroform vapor and dry air.

Responsiveness is so stable and reproducible even after composite exposure to chloroform vapor and dry air with 30 cycles, or exposure to chloroform vapor over $24 \mathrm{~h}$. These results indicate that the composite of PEO, filled with $\mathrm{PEO}$-grafted $\mathrm{CB}$, is a promising material for preparing a solvent vapor sensor.

\section{Effects of Dispersion of $C B$ in Composite on Responsive- ness to Chloroform Vapor}

In general, the conducting network of $\mathrm{CB}$ is formed by CB aggregations. ${ }^{19}$ The uneven dispersion of $\mathrm{CB}$ creates much CB aggregation. Therefore, the distance between aggregations becomes very large and so the conducting network cannot be built up. CB particles at the uniform dispersion find it difficult to form a conducting network. It is expected that at the conducting state of the uniform dispersion, CB content is so high that the whole composite is the conducting path. Therefore, it is difficult for the conducting path to be cut by solvent absorption and responsiveness of composite to solvent vapor is very low.

In the PEO and PEO-grafted CB system, the dispersion of $\mathrm{CB}$ in the composite is mainly dependent on dispersion process. In this study, we dispersed PEO-grafted $\mathrm{CB}$ into $4 \mathrm{wt} \%$ PEO solution, and the mixture was treated as follows: (1) mixture was stirred by a magnetic stirrer for $1 \mathrm{~h},(2)$ mixture was stirred for $1 \mathrm{~h}$, then treated under ultrasonic irradiation for $2 \mathrm{~min}$, and (3) mixture was stirred for $1 \mathrm{~h}$, then treated under ultrasonic irradiation for $12 \mathrm{~min}$. The degree of CB dispersion in composite was not determined in this experiment, but obviously, the degree of CB dispersion decreased as follows: $(1)>(2)>(3)$.

Responsiveness of the composite in the above three methods is shown in Figures 8 and 9. Figure 8 shows results from Porousblack, and Figure 9, results from Asahi $60 \mathrm{H}$ black.

In Figure 8, for Porousblack-containing composite, at the $\mathrm{CB}$ content of $12 \mathrm{wt} \%$, responsiveness of the composite in the three methods is similar, but the second method gives higher result than the others. The disperse method does not largely affect vapor responsiveness. This may be due to the high CB concentration in the amorphous polymer region where the conducting network is very stable in dry air. But in the case of $6 \mathrm{wt} \%$ Porousblack content, the conducting path is narrow and unstable, in accordance to a high initial resistance and low responsiveness. With good dispersing, such as an ultrasonic treatment, it would be difficult to form a conducting network.

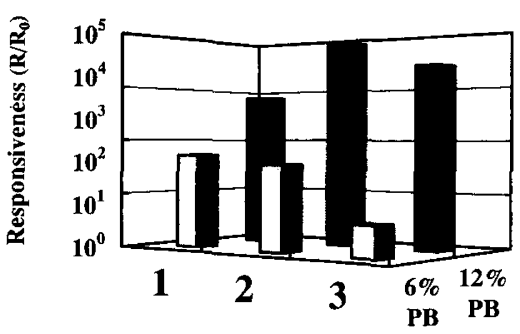

Figure 8. Effects of $\mathrm{CB}$ dispersion on responsiveness of the composite from PEO and PEO-grafted Porousblack (PB). Dispersing method: 1, stirring for $1 \mathrm{~h}$ with a magnetic stirrer at general speed; 2 , stirring for $1 \mathrm{~h}$ and followed by treatment with ultrasonic irradiation for $2 \mathrm{~min} ; 3$, stirring for $1 \mathrm{~h}$ and followed by treatment with ultrasonic irradiation for $12 \mathrm{~min}$.

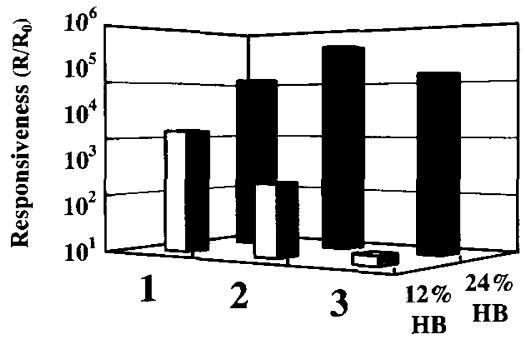

Figure 9. Effects of $\mathrm{CB}$ dispersion on responsiveness of the composite from PEO and PEO-grafted Asahi $60 \mathrm{H}$ black (HB). The symbols of $\mathbf{1}, \mathbf{2}$, and $\mathbf{3}$ are the same as that described in Figure 8 .

As shown in Figure 9, the results for Asahi $60 \mathrm{H}$ black are somewhat similar to those of Porousblack, but $\mathrm{CB}$ content with the same results is much higher than that of Porousblack. That is, at CB content of $24 \mathrm{wt} \%$, the disperse method almost did not affect responsiveness. However, at $12 \mathrm{wt} \% \mathrm{CB}$ content, better dispersion results in a lower responsiveness. This proves that the Porousblack is more effective on the responsiveness of the composite. At the same CB content of $12 \mathrm{wt} \%$ and same CB dispersion method, the responsiveness of Porousblack is large, but that of Asahi $60 \mathrm{H}$ black is small.

\section{Effects of Composite Film Thickness on Responsiveness to Chloroform Vapor}

Thin film of a composite may respond more quickly. This study examines the effects of the composite film thickness on initial resistance and responsiveness to chloroform vapor.

Figure 10 shows the effects of the composite film thickness on initial resistance. With the same surface area, in theory, electric resistance should be in inverse proportion to composite film thickness. There are many factors which influence electric resistance, such as $\mathrm{CB}$ dispersion, and composite coating. If thickness of composite film is larger than the thickness of coated $\mathrm{Ag} / \mathrm{Pd}$ on the comb-like electrode, it will affect electric resistance, because a part of the surface composite will not have any contribution to the conducting.

As shown in Figure 10, both CB show similar resistance change, and the initial resistance decreased with increase in composite film thickness.

Figure 11 shows the effects of composite film thickness on the responsiveness to chloroform vapor. For both $\mathrm{CB}$, 


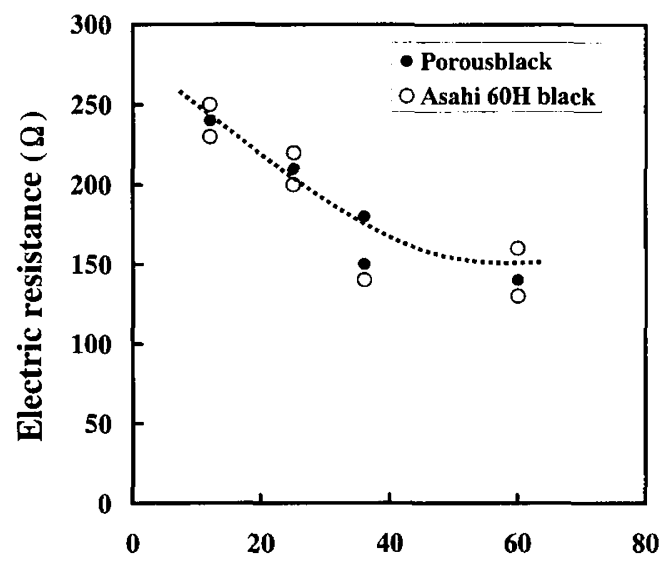

Film thickness $(\mu \mathrm{m})$

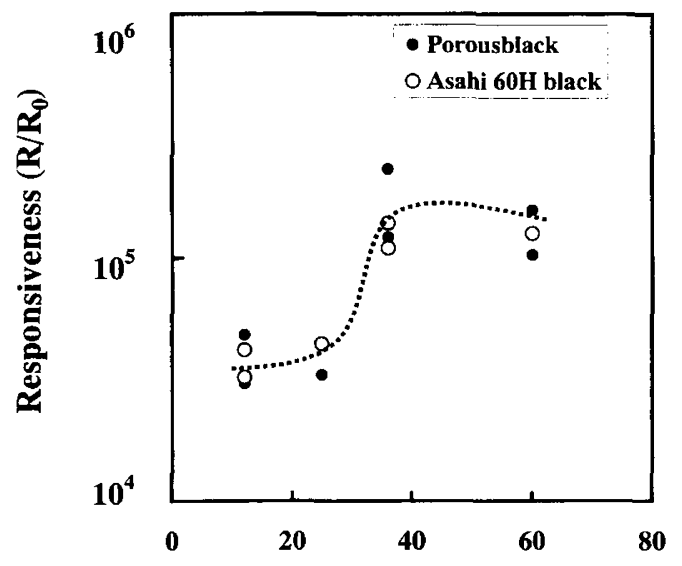

Film thichness $(\mu \mathbf{m})$
Figure 10. Effects of film thickness of the composite loaded on the comb-like electrode on initial electric resistance.

responsiveness at thickness about $20 \mu \mathrm{m}$ is lower than that at thickness above $40 \mu \mathrm{m}$. However, above $40 \mu \mathrm{m}$, responsiveness decreases slowly with increase in film thickness, possibility since, at thickness beyond the coated $\mathrm{Ag} / \mathrm{Pd}$ thickness, a part of the surface composite does not contribute to the conducting, but may act as a protective film to prevent inner composite resistance change, leading to slight decrease of the gas responsiveness of the thick composite film.

Relationship between Responsiveness of Electric Resistance and Vapor Absorption and Desorption of Composite from PEO and PEO-Grafted $C B$

Large change of electric resistance is caused by solvent vapor absorption and desorption. ${ }^{9-14}$ Electric resistance increases or decreases during solvent vapor absorption, and returns to its initial value as vapor desorbs completely.

We developed a method to simultaneously determine resistance and chloroform vapor absorbed by the composite, to understand the conductive mechanism of filled conductive polymer composites as well as responsiveness to chloroform vapor.

During resistance measurement, total weight of the electrode loaded with composite and frame hanging with the electrode was measured. The change of weight is considered the amount of vapor absorbed by the composite.

Typical curves of responsiveness of electric resistance and chloroform vapor absorbed by the composite are plotted in Figure 12. Resistance and absorption of chloroform greatly increased during the initial $60 \mathrm{~s}$ in chloroform vapor, indicating that the electric resistance of the composite change is due to absorption of solvent vapor.

By solvent vapor absorbing, the crystalline polymer is dissolved and viscosity of the composite decreases. During this period, the conducting network may be cut by the dissolved crystalline polymer and electric resistance increases.

After large increase in electric resistance and chloroform absorption, resistance slightly decreases (or in-
Figure 11. Effects of film thickness of the composite loaded on the comb-like electrode on the responsiveness of electric resistance to chloroform vapor.

creases as shown in Figure 5), but the chloroform absorption always slightly increases. Resistance changes by a competitive process during this period. That is, dissolved crystalline polymer cuts the $\mathrm{CB}$ conducting network, leading to increasing resistance, but decreased viscosity of the composite makes $\mathrm{CB}$ aggregates more easily, leading to decreasing resistance.

When the composite was transferred to dry air, resistance and absorption decreased suddenly in the first $60 \mathrm{~s}$, and resistance remained steady, but the desorption process was slower than absorption process. The small chloroform absorption may not influence resistance of the composite. The same was also observed in the PE- $b$ $\mathrm{PEO} / \mathrm{CB}$ composite study on the relationship between responsiveness and vapor concentration. ${ }^{11}$

During solvent vapor desorption, the dissolved polymer is recrystallized and the $\mathrm{CB}$ network is resumed completely, leading to the electric resistance return to the initial value.

\section{Conduction Mechanism of the Composite from PEO and PEO-Grafted $C B$}

Change of electric resistance is considered dependent on: (1) swelling of the polymer chain and (2) movement of CB. These two processes are more drastic when the viscosity of the composite decreased, and that may happen as temperature increases or the polymer dissolves in a good solvent.

Swelling of the polymer chain due to melting of the crystalline polymer may cut the conductive network in the composite, to largely increase the electric resistance of the composite. This is often observed and defined as PTC of electric resistance of the conducting composite. In this study, this happened as the composite absorbed solvent vapor. The composite may thus be used as a gas sensor.

The movement of CB may cause the particles to divide into two opposite states. With viscosity of the composite decreasing, CB particles aggregate because of high surface energy. With dissolution of crystalline polymer, CB 


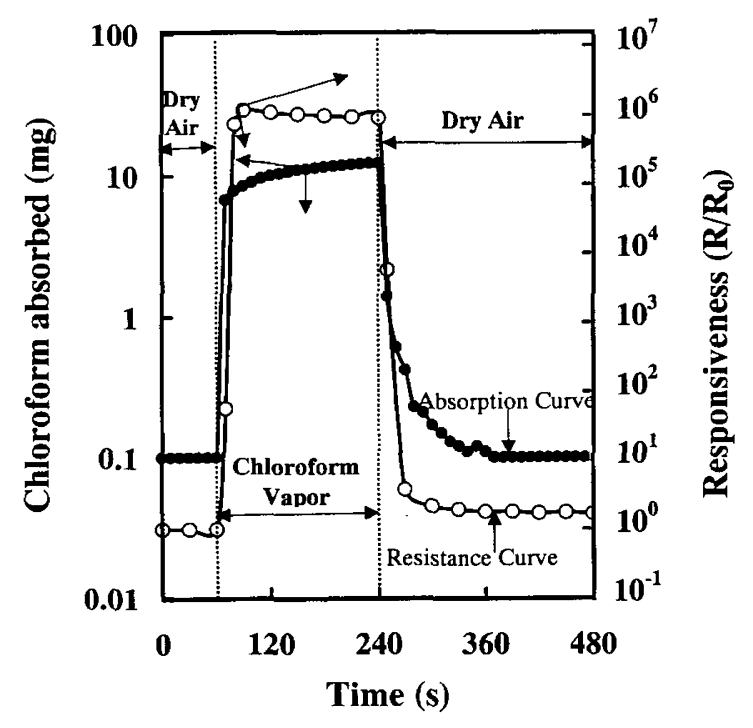

Figure 12. Amount of chloroform absorbed and responsiveness of electric resistance of the composite from $\mathrm{PEO}$ and PEO-grafted carbon black, in chloroform vapor at $25^{\circ} \mathrm{C}$.

particles move into the dissolved crystalline polymer, which makes the $\mathrm{CB}$ dispersing more uniform. NTC, which occurs above the melting point of the matrix polymer, may be caused by CB aggregation. ${ }^{20,21}$ As shown in Figure 4, for high Porousblack filled composite, there is slight decrease of electric resistance after drastic increase in chloroform vapor.

Two conduction mechanisms may be considered. When CB particles are connected or particle distance becomes shorter (less than $0.35 \mathrm{~nm}$ ), it is considered an electronic conduction. ${ }^{22}$ In the case, when CB particles are isolated in the composite or CB aggregates are separated by thin polymer films, the conduction mechanism by tunneling has to be considered..$^{23}$

Clearly, at high $\mathrm{CB}$ content, with the $\mathrm{CB}$ conducting network, the conductive mechanism is mainly electronic conduction. In this case, electric conduction obeys Ohm's law. ${ }^{24}$ When the conducting network is cut by dissolved crystalline polymer due to the chloroform vapor absorption, as seen in Figures 4 and 5, electric resistance is largely increased.

But at low CB content, since there are almost no conducting networks and CB particles are isolated, initial resistance of the composite is very high. The conduction mechanism may only be considered as a tunneling conduction, and electric conduction does not obey Ohm's law. ${ }^{24}$ In this case, the electric resistivity of the composite is determined by maximum distance of the nearest particles or aggregates.

As shown in Figures 4 and 5, at low content of CB, electric resistance of composite drastically decreases to $10^{-1}-10^{-2}$ of the initial resistance in the chloroform vapor, which presents a negative vapor coefficient (NVC). Similar to NTC, NVC may be due to movement of CB as the crystalline polymer is dissolved. Change of electric resistance in NVC may be explained by the conduction mechanism of the tunneling theory. That is, with the crystalline polymer dissolved and viscosity decreased,
CB aggregates may move to the dissolved crystalline polymer region, and dispersion of the CB particles may be more uniform. Therefore, the maximum distance of the nearest $\mathrm{CB}$ particles decreases, and leads to decrease in electric resistance.

When absorbed vapor is desorbed, the matrix polymer recrystallizes, and CB particles separate. CB particles aggregate again and maximum distance of the nearest aggregates increases, leading to increase in electric resistance. So as shown in Figures 4 and 5, initial resistance is resumed when the composite transfers to dry air.

\section{CONCLUSION}

The percolation threshold of conducting composite from $\mathrm{PEO}$ and $\mathrm{PEO}$-grafted $\mathrm{CB}$ determined in dry air is much smaller than in chloroform vapor, or calculated from the percolation theory. CB particles are mainly loaded in the amorphous polymer region, and may form a conducting network at the crystalline boundary. In chloroform vapor, easily absorbed by PEO, electric resistance is changes largely due to dissolution of crystalline polymer and the movement of CB particles. At CB content of about $20-50 \mathrm{wt} \%$, electric resistance drastically increases $10^{4}-10^{6}$ times when the composite is transferred from air to chloroform vapor, which means the composite may be used as a gas sensor to identify and quantify certain vapors quickly at room temperature.

Optimum conditions for the preparation of the composite for a gas sensor is as follows: (1) the content of PEO-grafted Porousblack is $24 \mathrm{wt} \%$, (2) PEO-grafted CB is dispersed in solvent by stirring for $1 \mathrm{~h}$ followed by treatment with ultrasonic irradiation for $2 \mathrm{~min}$, and (3) the thickness of the composite film coated on the electrode is $40 \mu \mathrm{m}$. The composite made by this method is very sensitive to respond to chloroform vapor, and electric properties are very stable and reproducible.

At low CB content, there is only electric conduction by electron tunneling, resulting in a high electric resistivity of the composite. When the low $\mathrm{CB}$ content composite is transferred from dry air to chloroform vapor, electric resistance decreases to $10^{-1}-10^{-2}$ of the initial resistance. At high $\mathrm{CB}$ content, the $\mathrm{CB}$ conducting network is easily formed, and electrons pass through connected CB particles. In chloroform vapor, the absorbed vapor dissolves the crystalline polymer region, the $\mathrm{CB}$ conducting network is destroyed and electric resistance dramatically increases because of rearrangement of CB dispersion.

Acknowledgment. This study was partly supported by a Grant-in-Aid for Scientific Research (No. 11650708) from the Ministry of Education, Science, Sports and Culture of Japan.

\section{REFERENCES}

1. E. P. Mamunya, V. V. Davidenko, and E. V. Lebedev, Composite Interface, 4, 169 (1997)

2. K. Miyasaka, K. Watanabe, E. Jojima, H. Aida, M. Sumita, and K. Ishikawa, J. Mater. Sci., 17, 1610 (1982).

3. E. P. Mamunya, V. V. Davidenko, and E. V. Lebedev, Dopovidi AN Ukr., 5, 124 (1991). 
4. R. R. Singh and R. W. Roberts, Polym. Composites, 6, 58 (1985).

5. H. Tang, X. Chen, and Y. Luo, Eur. Polym. J., 33, 1383 (1997).

6. B. Wargotz and W. M. Alvino, Polym. Eng. Sci., 7, 763 (1967).

7. J. Meyer, Polym. Eng. Sci., 14, 706 (1974).

8. S. Hayashi, A. Naitoh, S. Machida, M. Okazaki, K Maruyama, and N. Tsubokawa, Appl. Organomtal. Chem., 12, $743(1998)$

9. N. Tsubokawa, S. Yoshikawa, K. Maruyama, T. Ogasawara, and K. Saitoh, Polym. Bull., 39, 217 (1997).

10. M. Okazaki, K. Maruyama, M. Tsuchida, and N. Tsubokawa, Polym. J., 31, 672 (1999).

11. J. Chen and N. Tsubokawa, J. Appl. Polym. Sci., 77, 2437 (2000).

12. J. Chen and N. Tsubokawa, Polym. Adv. Technol., 11, 101 (2000).
13. B. J. Doleman, E. J. Severin, and N. S. Lewis, Proc. Natl. Acad. Sci. U. S. A., 95, 5442 (1998).

14. M. C. Lonergan, E J. Severin, B. J. Doleman, S. A. Beaber, R. H. Grubbs, and N. S. Lewis, Chem. Mater., 8, 2298 (1996).

15. H. Scher and R. Zallen, J. Chem. Phys., 53, 3759 (1970).

16. Y. Fujikura, M. Kawarai, and F. Ozaki, Polym. J., 21, 609 (1989).

17. X. Zhou, W. Li, and G. Pan, Tsinghua Sci. Technol., 1, 376 (1996).

18. Q. Zheng, M. Peng, and X. Yi, Gaofenzi Cailiao Kexue Yu Gongcheng, 14, 121(1998)

19. J. Janzen, J. Appl. Phys., 46, 966 (1975).

20. H. Tang, Z. Liu, and J. Piao, J. Appl. Polym. Sci., 51, 1159 (1994).

21. M. Narkis, Polym. Eng. Sci., 21, 16 (1981).

22. A. I. Medalia, Rubber Chem. Technol., 59, 432 (1986),

23. A. Voet, Rubber Chem. Technol., 54, 42 (1981).

24. M. Narkis, Polym. Eng. Sci., 18, 649 (1978). 